\title{
Desiccated Coconut Residue Based Activated Carbon as an Electrode Material for Electric Double Layer Capacitor
}

\author{
Mohd Adib Yahya ${ }^{1}$, C. W. Z. C. W. Ngah ${ }^{1}$, M. A. Hashim ${ }^{1}$, Musa Ahmad ${ }^{1} \&$ Mohd Ambar Yarmo \\ ${ }^{1}$ Faculty of Science and Technology, Universiti Sains Islam Malaysia (USIM), Malaysia \\ ${ }^{2}$ Faculty of Science and Technology, Universiti Kebangsaan Malaysia (UKM), Malaysia \\ Correspondence: Mohd Adib Yahya, Faculty of Science and Technology, Universiti Sains Islam Malaysia (USIM), \\ Malaysia. E-mail: mohd.adib82@gmail.com
}

$\begin{array}{cc}\text { Received: March 8, } 2015 & \text { Accepted: March 15, } 2015 \quad \text { Online Published: March 17, } 2015 \\ \text { doi:10.5539/apr.v7n2p93 } & \text { URL: http://dx.doi.org/10.5539/apr.v7n2p93 }\end{array}$

\begin{abstract}
Activated carbon derived from desiccated coconut residue was treated with sodium hydroxide $(\mathrm{NaOH})$ and analyzed for its supercapacitor performance. The sample was then characterized by $\mathrm{N}_{2}$ adsorption at $-196^{\circ} \mathrm{C}$, Energy dispersive X-ray (EDX) analysis and X-ray diffraction (XRD) in order to investigate its surface area,

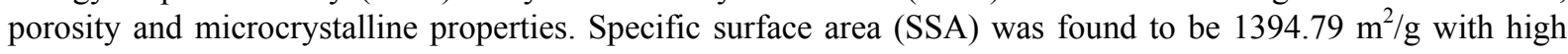
microporosity of $76.92 \%$. Electrochemical double-layer capacitance was studied by cyclic voltammetry with potential window of $1 \mathrm{~V}$. The presence of high microporosity properties affects the supercapacitor performance due to lack of accessibility of the electrolyte into the activated carbon pores. The calculated specific capacitance was found to be $42 \mathrm{~F} / \mathrm{g}$.
\end{abstract}

Keywords: supercapacitor, activated carbon, desiccated coconut residue, cyclic voltammetry

\section{Introduction}

Technologies based on electrochemical capacitors have already been broadly implemented around the world as the power demands of portable devices increase as well as the current enhanced use of renewable energy source (Liu $\&$ Pickup, 2008). Supercapacitors can be used in several ways; as uninterruptable power sources (UPSs), being combined with batteries to provide peak power, and also replacing batteries in memory back-up (Arbizzani et al., 2001). Excellent supercapacitors should be having a greater capacitance and energy density than that of conventional capacitors hence enabling compact designs (Noked et al., 2011). Basic principle of supercapacitors in storage energy is by a formation of a double layer of electrolyte ions on the surface of the electrodes (Zhu et al., 2011), rather than the more common arrangement of a solid dielectric between electrodes. The electrodes utilized usually designed from porous carbon or any high surface area materials as conductors which equipped with a molecule-thin layer of electrolyte as the dielectric to separate charge (Lota et al., 2008). Due to the properties of high surface area of the electrodes and a very small distance between the electrodes hence producing large capacitance and energy storage up to approximately two orders of magnitude (10-100 s kW) (Chen et al., 2009).

A supercapacitor operates by adsorbing/desorbing the charged ions from an electrolyte onto the electrodes (Candelaria et al., 2012). The distance between the charges of the opposite sign across the interface of the electrode/electrolyte can be in the range of angstroms $(\mathrm{Qu}, 2002)$. There are also strong interactions between ions/molecules in both electrolyte and electrode surface. The source of the energy storage comes from physical separation of the electronic and ionic charges. When active materials are in contact with a metal electrode, it will be charged. Then, the solvated ions from the opposite charge will be attracted to the active materials hence accumulated at the active material and electrolytic solution interface. The separator is basically used to prevent the electrical contact between anode and cathode. At the same time, it permits the migration of the solvated electrolyte ion (Azam \& Rosle, 2013). Energy storage in supercapacitors is by means of static charge rather than that of an electro-chemical process in the battery systems (Hadjipaschalis et al., 2009). The capacity of the supercapacitor, in principle, is proportional to the electrode surface, where, how much ions can be attracted (Xu et al., 2008). In comparison with batteries, it has no limitation of the electrochemical charge transfer kinetics applied in batteries. However, in terms of energy storage, supercapacitor has lower magnitude of storage than batteries (Zhu et al., 2011). In other words is that the supercapacitor particularly electric double layer capacitor (EDLC) stores the energy physically and not chemically as opposed to rechargeable batteries (Orita et al., 2010). 
This study was aimed at introducing a supercapacitor derived from desiccated coconut residue (DCR) based activated carbon $(\mathrm{AC})$ treated with sodium hydroxide $(\mathrm{NaOH})$.

\section{Experimental}

Desiccated coconut residue (DCR) was collected from local market in Nilai, Malaysia and was dried until used. The sample was then ground into 1 to $2 \mathrm{~mm}$ of particle size. It was then carbonized under $\mathrm{N}_{2}$ flow for 1 hour of duration time at $500^{\circ} \mathrm{C}$ and then cooled to room temperature. The resulting char was then impregnated with sodium hydroxide $(\mathrm{NaOH})($ Merck, Germany) at ambient temperature for 1 hour with ratio of 1:3 (w/w). It was then dried in an oven for overnight at $105^{\circ} \mathrm{C}$ and heated under $\mathrm{N}_{2}$ flow rate for 1 hour at $500^{\circ} \mathrm{C}$. The sample was then washed with $1 \mathrm{M}$ of $\mathrm{HCl}$ followed by plenty of deionized water and dried at $110^{\circ} \mathrm{C}$ before being cooled and stored until use. The surface area of the activated carbon, micropore volume and mesopore volume was studied by $\mathrm{N}_{2}$ adsorption at $-196^{\circ} \mathrm{C}(77 \mathrm{~K})$, using an automatic volumetric sorption analyzer (Quantachrome, Autosorb 2). DCR-AC was first degasified at $350^{\circ} \mathrm{C}$ for a certain period. The surface area was obtained from the Brunauer-Emmett-Teller (BET) equation. Micropore volume was obtained by $t$-plot method. Total pore volume was obtained at 0.99 of relative pressure. Energy Dispersive X-Ray (EDX) was performed by Hitachi SU 1510/Horiba Emax 450. The scanning electron microscope (SEM) was first transferred to the site interest at Horiba E-max software. The point of interest was selected for EDX data collection. The peak spectrum was reconstructed to double confirm the presence of elements. X-Ray Diffraction (XRD) was performed with Bruker AXS Germany (D8 Advance).

The preparation of the electrode was done by a mixture of $85 \mathrm{wt} \%$ of DCR-AC, $10 \mathrm{wt} \%$ of carbon black (TIMCAL), and $5 \mathrm{wt} \%$ of polyvinylidene-flouride (Sigma-Aldrich) in 1-methyl-2-pyrrolidone (Merck, Germany) to form slurry until homogenized. It was then poured into an aluminium foil with thickness of $2.5 \mu \mathrm{m}$ using 'Dr Blade'. The prepared electrode was dried for overnight at $120^{\circ} \mathrm{C}$. A sandwich type cell was fabricated from two electrodes with similar weights with electrode area of $1 \mathrm{~cm}^{2}$ and separated by filter paper as a separator and an electrolyte $\left(1 \mathrm{M} \mathrm{Na}_{2} \mathrm{SO}_{4}\right)$. Capacitive performances were evaluated by cyclic voltammetry $(\mathrm{CV})$ at scan rates of 5 , 20,50 and $100 \mathrm{mV} / \mathrm{s}$.

\section{Results and Discussion}

\subsection{Physical Properties of DCR-AC}

Figure 1 shows $\mathrm{N}_{2}$ adsorption isotherm plot of DCR-AC prepared. It exhibited Type I isotherm type with horizontal plateau at higher relative pressure. It indicated a highly microporous materials with a narrow pore size distribution. Type I isotherm is defined as an enhanced interactions of adsorbent-adsorbate in micropores of molecular dimensions. The narrow range of relative pressure that required achieving the plateau indicated that there is a limited pore size range in the sample. Table 1 summarizes specific surface area (SSA) of DCR-AC and its micropore $\left(\mathrm{V}_{\mathrm{mi}}\right)$, mesopore $\left(\mathrm{V}_{\mathrm{me}}\right)$, total volume $\left(\mathrm{V}_{\mathrm{t}}\right.$ as well as porosity. The specific surface area of DCR-AC was found to be $1394.79 \mathrm{~m}^{2} / \mathrm{g}$. It was shown that DCR-AC was highly microporous with $76.92 \%\left(\mathrm{~V}_{\mathrm{mi}} / \mathrm{V}_{\mathrm{t}} \times 100\right)$ of porosity.

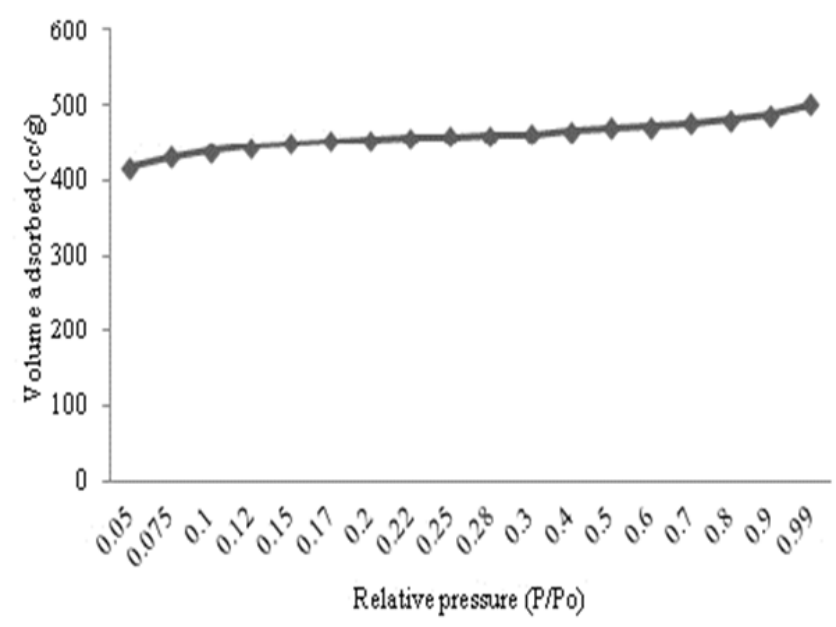

Figure $1 . \mathrm{N}_{2}$ adsorption isotherm of DCR-AC 
Table 1. Result of specific surface area and porosity of DCR-AC

\begin{tabular}{llllll}
\hline Properties & $\mathrm{SSA}\left(\mathrm{m}^{2} \mathrm{~g}^{-1}\right)$ & $\mathrm{V}_{\mathrm{mi}}\left(\mathrm{cm}^{3} \mathrm{~g}^{-1}\right)$ & $\mathrm{V}_{\mathrm{me}}\left(\mathrm{cm}^{3} \mathrm{~g}^{-1}\right)$ & $\mathrm{V}_{\mathrm{t}}\left(\mathrm{cm}^{3} \mathrm{~g}^{-1}\right)$ & Porosity (\%) \\
\hline DCR-AC & 1394.79 & 0.60 & 0.18 & 0.78 & 76.92 \\
\hline
\end{tabular}

Figure 2 shows the results of EDX analysis of the DCR-AC studies. It was observed that weight percentage (wt $\%$ ) of carbon was $70.94 \%$, followed by oxygen (23.34\%), potassium $(0.27 \%)$, sodium $(5.25 \%)$, magnesium $(0.19 \%)$, and silica $(0.34 \%)$. Figure 3 shows the XRD spectra of DCR-AC. Result showed a turbostratic disordered carbon with microcrystallinity properties between graphite and amorphous carbon.

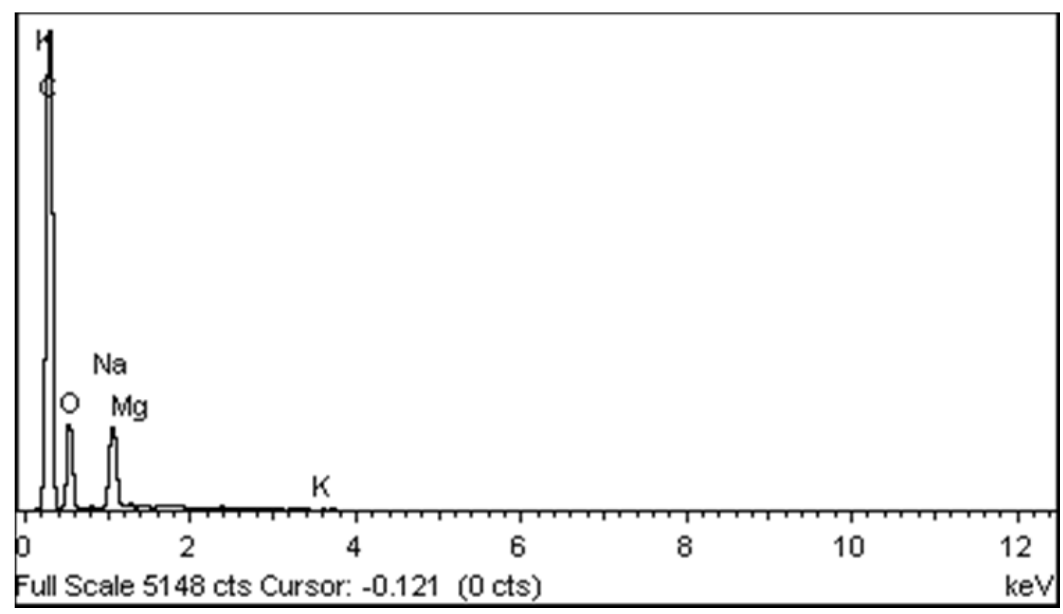

Figure 2. EDX analysis of DCR-AC

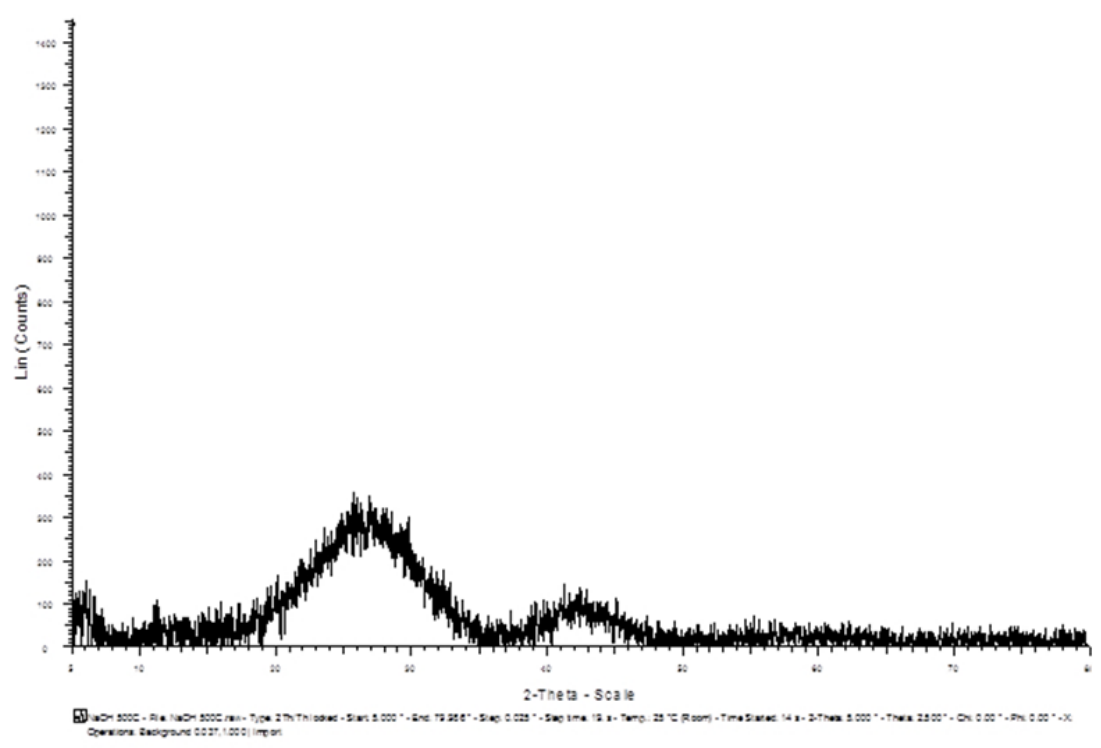

Figure 3. XRD analysis of DCR-AC

\subsection{Electrochemical Behaviour}

Figure 4 shows a cyclic voltammetry of the DCR-AC based supercapacitor at scan rate of $5 \mathrm{mV} / \mathrm{s}$. The behaviour of electric double layer capacitor (EDLC) is generally expressed in the form of a rectangular shape of voltammetry characteristic (Frackowiak \& Beguin, 2001). The specific capacitance of one electrode was given by the following equation (Zapata-Benabithe et al., 2012):

$$
\mathrm{C}_{\mathrm{cv}}=\frac{\sum|I| \Delta t}{2 m \Delta V}
$$


Where, $\sum|I| \Delta t$ is the area of the current (A) against time (s) curve, $m$ is the mass of active material (g), $\Delta V$ is the potential window. The calculated specific capacitance was found to be $42 \mathrm{~F} / \mathrm{g}$. In theory, the specific capacitance of activated carbon increases with its surface area. However, the presence of micropore $(76.92 \%)$ may reduce the ion-sieving effect in the system. According to Arbizzani et al. (2001), the smaller the pore size, the more difficult it is for electrolyte to get in. Therefore, the capacitance it not only depends on the surface area, but also on the distribution of the pore hence giving low specific capacitance in the DCR-AC based supercapacitor.

Figure 5 shows the variations of specific capacitance at different scan rates of CV. It was shown that the capacitance decreased when the scan rate increased. The specific capacitance decreased with scan rates due to the EDL formation within the micropores was slower and less complete in comparison to rate of variation in potential (Zapata-Benabithe et al., 2012).

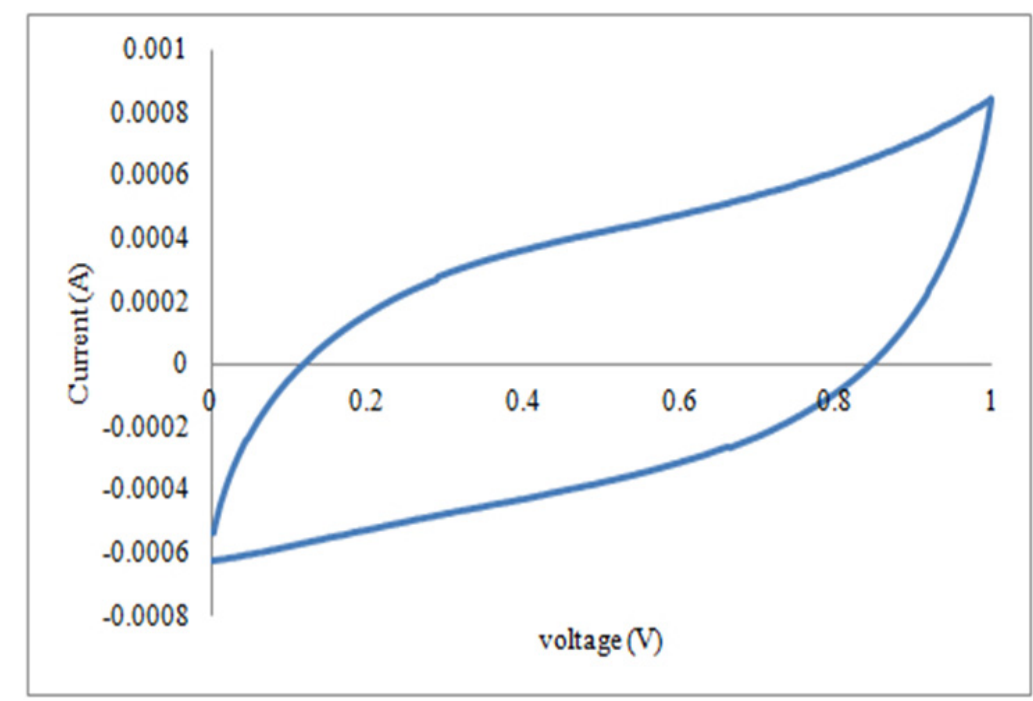

Figure 4. Cyclic voltammetry profile at $5 \mathrm{mV} / \mathrm{s}$

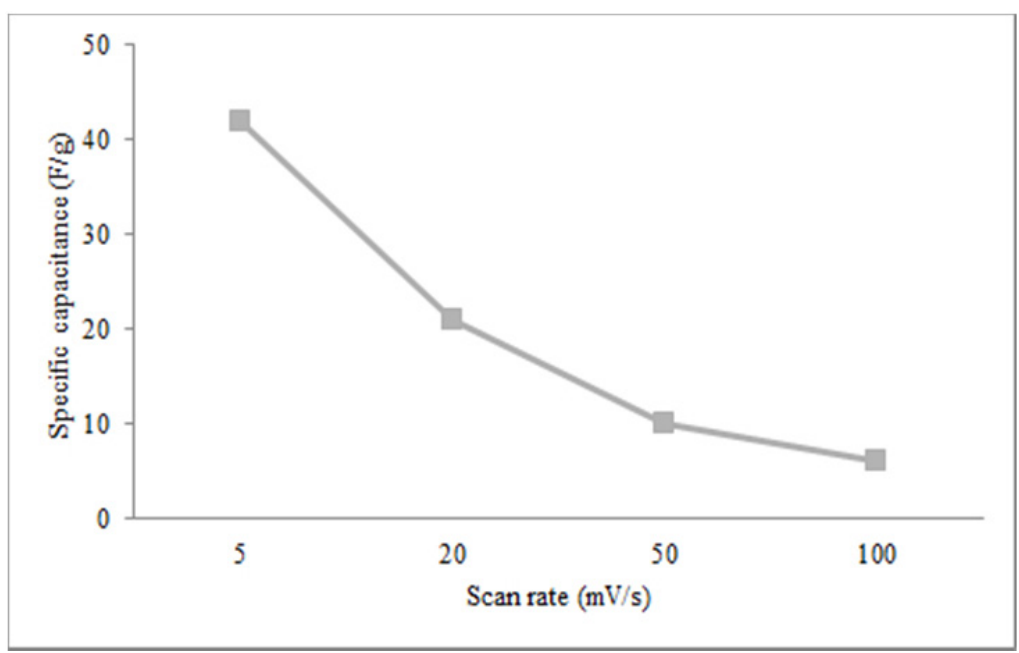

Figure 5. Variation of specific capacitance at different scan rates

\section{Conclusion}

A double layer type of supercapacitor was designed by using a newly precursor derived from DCR which treated with $\mathrm{NaOH}$ as active material in both positive and negative electrodes and $1 \mathrm{M}$ of $\mathrm{Na}_{2} \mathrm{SO}_{4}$ as electrolyte. Results showed that micro porosity of the sample affected the results hence giving a relatively low specific capacitance value. 


\section{Acknowledgements}

The authors are grateful to Universiti Sains Islam Malaysia and Ministry of Higher Education (MyBrain15) for findings of this project.

\section{References}

Arbizzani, C., Mastragostino, M., \& Soavi, F. (2001). New trends in electrochemical supercapacitors. Journal of Power Sources, 100, 164-170. http://dx.doi.org/10.1016/S0378-7753(01)00892-8

Azam, M. A., \& Rosle, M. F. (2013). Electrochemical analyses of carbon nanotube based supercapacitor in $1 \mathrm{M}$ $\mathrm{LiPF}_{6}$ organic electrolyte. International Journal of Elecroactive Materials, 1, 55-59.

Candelaria, S. L., Shao, Y., Zhou, W., Li, X., Xiao, J., Zhang, J. G., ... Cao, G. (2012). Nanostructured carbon for energy storage and conversion. Nano Energy, 1, 195-220. http://dx.doi.org/10.1016/j.nanoen.2011.11.006

Chen, H., Cong, T. N., Yang, W., Tan, C., Li, Y., \& Ding, Y. (2009). Progress in electrical energy storage system: A critical review. Progress in Natural Science, 19, 291-312. http://dx.doi.org/10.1016/j.pnsc.2008.07.014

Frackowiak, E., \& Beguin, F. (2001). Carbon materials for the electrochemical storage of energy in capacitors. Carbon, 39, 937-950. http://dx.doi.org/10.1016/S0008-6223(00)00183-4

Hadjipaschalis, I., Poullikkas, A., \& Efthimiou, V. (2009). Overview of current and future storage technologies for electric power application. Renewable and Sustainable Energy Reviews, 13, 1513-1522. http://dx.doi.org/10.1016/j.rser.2008.09.028

Liu, X., \& Pickup, P. G. (2008). Ru oxide supercapcitors with high loadings and high power and energy densities. Journal of Power Sources, 176, 410-416. http://dx.doi.org/10.1016/j.jpowsour.2007.10.076

Lota, G., Centeno, T. A., Frackowiak, E., \& Stoeckli, F. (2008). Improvement of the structural and chemical properties of a commercial activated carbon for its application in electrochemical capacitors. Electrochimica Acta, 53(5), 2210-2216. http://dx.doi.org/10.1016/j.electacta.2007.09.028

Noked, M., Soffer, A., \& Aurbach, D. (2011). The electrochemistry of activated carbonaceous materials: past, present, and future. Journal of Solid State Electrochemistry, 15, 1563-1578. http://dx.doi.org/10.1007/ s10008-011-1411-y

Orita, A., Kamijima, K., \& Yoshida, M. (2010). Allyl-functionalized ionic liquids as electrolytes for electric double-layer capacitors. Journal of Power Sources, 195, 7471-7479. http://dx.doi.org/10.1016/j.jpowsour. 2010.05.066

Qu, D. (2002). Studies of the activated carbons used in double-layer supercapacitors. Journal of Power Sources, 109, 403-411. http://dx.doi.org/10.1016/S0378-7753(02)00108-8

Xu, B., Wu. F., Chen, R., Cao, G., Chen, S., Zhou, Z., \& Yang, Y. (2008). Highly mesoporous and high surface area carbon: A high capacitance electrode material for EDLCs with various electrolytes. Electrochemistry Communications, 10, 795-797. http://dx.doi.org/10.1016/j.elecom.2008.02.033

Zapata-Benabithe, Z., Carrasco-Marin, F., \& Moreno-Castilla, C. (2012). Preparation, surface characteristics, and electrochemical double-layer capacitance of $\mathrm{KOH}$-activated carbon aerogels and their O- and N-doped derivatives. Journal of Power Sources, 219, 80-88. http://dx.doi.org/10.1016/j.jpowsour.2012.07.036

Zhu, Y., Murali, S., Stoller, M. D., Ganesh, K. J., Cai, W., Ferreira, P. J., .. Ruoff, S. (2011). Carbon-based supercapacitors produced by activation of graphene. Science, 332, 1537-1541. http://dx.doi.org/10.1126/ science. 1200770

\section{Copyrights}

Copyright for this article is retained by the author(s), with first publication rights granted to the journal.

This is an open-access article distributed under the terms and conditions of the Creative Commons Attribution license (http://creativecommons.org/licenses/by/3.0/). 